\title{
Sellar Gangliocytoma: Case Report and Review of an Extremely Rare Tumour
}

\author{
Pedro José Quiroga-Padilla ${ }^{a}$ Deyanira González-Devia ${ }^{a}$ b \\ Rafael Andrade ${ }^{a, c}$ Paola Escalante ${ }^{c}$ Enrique Jiménez-Hakim ${ }^{d}$ \\ ${ }^{a}$ Faculty of Medicine, Universidad de Los Andes, Bogotá, Colombia; ${ }^{b}$ Department of Internal \\ Medicine, Endocrinology, Hospital Universitario Fundación Santa Fé de Bogotá, Bogotá, \\ Colombia; 'Department of Pathology, Hospital Universitario Fundación Santa Fé de Bogotá, \\ Bogotá, Colombia; dDepartment of Neurosurgery, Hospital Universitario Fundación Santa \\ Fé de Bogotá, Bogotá, Colombia
}

\section{Keywords}

Sellar gangliocytoma $\cdot$ Pituitary hyperplasia $\cdot$ Pituitary adenoma $\cdot$ Tumorigenesis

\begin{abstract}
Sellar gangliocytomas (SGs) are rare, well-differentiated, low-grade neoplasias that commonly present along with a pituitary adenoma (PA). We describe a case of a 52-year-old woman with a 2-year history of headache, body weight increase, and recent onset of arterial hypertension and type 2 diabetes mellitus. Work-up tests revealed a normal hypophyseal profile, except for mild ACTH elevation, and a sellar mass on magnetic resonance imaging (MRI). A diagnosis of an enlarging pituitary macroadenoma was established, and to prevent symptom progression, the tumour was resected. Pathology showed 2 cell populations: ganglion and corticotrope cells. Three years after surgery, the patient no longer had a headache but persisted with arterial hypertension and type 2 diabetes mellitus. A literature review produced 207 cases of SGs. They typically present in women at 40 years of age and the most common clinical presentation are symptoms of acromegaly. Of the documented cases, 74 and $93 \%$ were treated with surgery alone or combined treatments (radiotherapy, radiosurgery, or pharmacotherapy), respectively. The majority of deaths associated with a SG came from the first half of the 20th century. In conclusion, this patient presented with a silent SG with likely pituitary hyperplasia. SGs are a challenging diagnosis, have a benign course, and may provide insights into PA tumourigenesis.
\end{abstract}




\section{Introduction}

Pituitary tumours are the third most common brain tumour in adults, accounting for $15 \%$ of them [1]. The clinical presentation of a sellar mass is determined by its extension; however, due to the increasing availability of neuroimaging, a greater number of cases are asymptomatic and incidentally diagnosed. For that reason, although sellar mass diagnosis begins with brain imaging, its ultimate diagnosis is dependent on pathological examination.

In 2017, gangliocytomas were classified by the World Health Organization as a grade I neoplasia in the category of neuronal and paraneuronal tumours (ORPHA: 251937) [2]. Gangliocytomas are composed of large, mature ganglion cells with abundant cytoplasm and Nissl bodies; ganglion cells may be binucleated or even multinucleated, with prominent nucleoli [3]. Sellar gangliocytomas (SGs) commonly present with a pituitary adenoma (PA) [4]. Diagnosis of SGs is challenging, as there are no specific clinical features or biomarkers present before histological evaluation [4]. In the present article, we report a case of a silent SG with an undefined corticotrope proliferation, and we present a literature review of SGs.

\section{Case Report}

A 52-year-old woman was referred to our institution due to a 2-year history of chronic occipital headache in association with a non-functioning sellar mass followed by magnetic resonance imaging (MRI) for 2 years. Past medical history was remarkable for the recent diagnosis of arterial hypertension and type 2 diabetes mellitus. Physical and neurologic exams were normal, except for central obesity. Three months before the present examination, a panel of hypophyseal hormones showed a mild ACTH elevation (ACTH $=49.20 \mathrm{pg} / \mathrm{mL}$, normal range [NR]: $0.0-46.0 \mathrm{pg} / \mathrm{mL}$ ); however, TSH, total T4, total T3, prolactin, insulin growth factor 1, growth hormone (GH), plasmatic 8 a.m., and 4 p.m. cortisol levels were normal. Brain MRI revealed a $14 \mathrm{~mm}$ sellar mass without suprasellar extension or optic chiasm compression (Fig. 1).

A neurosurgical board reviewed the case and decided to operate to prevent optic chiasm compression. The tumour was fully resected (Fig. 2) through a transsphenoidal transnasal approach, without peri- or post-operative complications. Two days after surgery, both 8 a.m. cortisol (707.9 nmol/L, NR: 185-624 nmol/L) and ACTH (81.3 pg/mL, NR: 4.7-48.8 pg/mL) were high. Two and seven months after surgery, 8 a.m. cortisol $(269.3 \mathrm{nmol} / \mathrm{L}$ and 249.5 $\mathrm{nmol} / \mathrm{L}$, respectively; NR: $171-536 \mathrm{nmol} / \mathrm{L})$, ACTH $(31.9 \mathrm{pg} / \mathrm{mL}$ and $25.4 \mathrm{pg} / \mathrm{mL}$, respectively; NR: 5-60 pg/mL), and both post-dexamethasone cortisol (at 7 months, $20.12 \mathrm{nmol} / \mathrm{L}$; $\mathrm{NR}<50 \mathrm{nmol} / \mathrm{L}$ ) and ACTH (at 7 months, $3.68 \mathrm{pg} / \mathrm{mL}$; NR: 5-60 pg/mL) were normal, and the remaining pituitary function was preserved. At 9 months, the MRI control did not show sellar masses. Three years after, the patient no longer had neurologic symptoms, and her blood pressure was pharmacologically controlled without treatment changes. However, glycated haemoglobin (HbA1c) persisted at high levels ( $9.3 \%$ at 11 months after surgery), in part due to lack of adherence to therapy, despite increased hypoglycaemic therapy.

Histological examination showed 2 cell populations (Fig. 3a, 2b): ganglion and adenohypophyseal cells. Ganglion cells were multipolar and large, with prominent nucleoli, abundant cytoplasm, and aggregation of Nissl substance. These cells were found in clusters and embedded into a neuropil. The adenohypophyseal cells were round to polygonal in shape, arranged in small groups, and mixed with ganglion cells.

On PAS staining, the adenohypophyseal cells displayed an intensely granular cytoplasmic pattern. Only blood vessels were reactive with the reticulin stain. The ganglion cells were positive for synaptophysin and neurofilament protein (markers of neuronal differentiation),

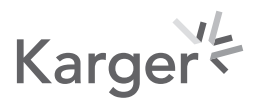



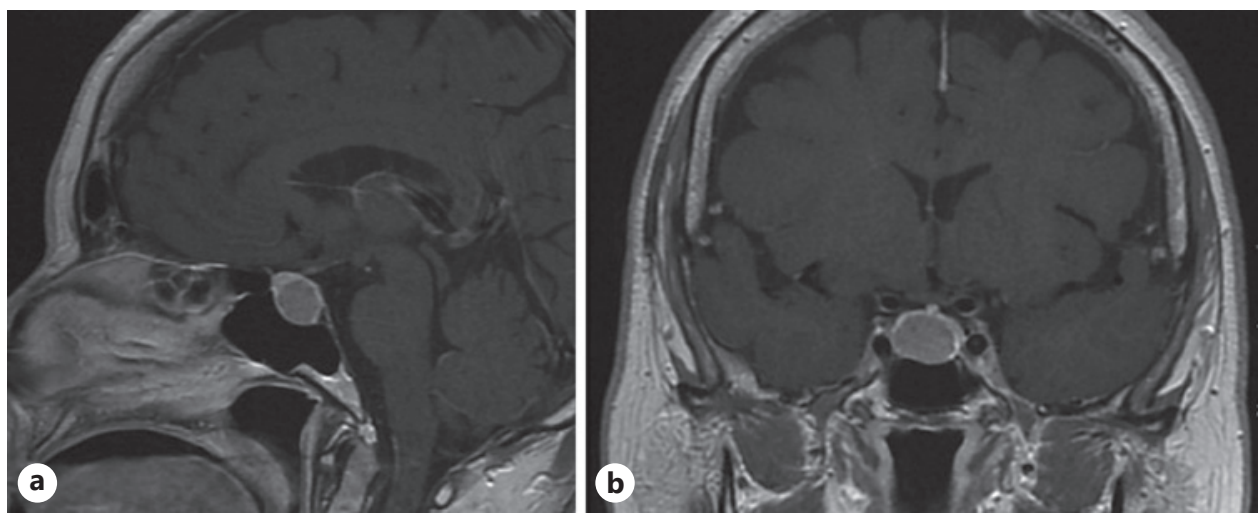

Fig. 1. Preoperative sellar mass (sagittal, gadolinium-enhanced) (a) and (coronal, gadolinium-enhanced) (b) T1-weighted MRI, 2 years after symptom onset. a and b show a pituitary macroadenoma Knosp 1, Hardy B. Both images did not show suprasellar extension or chiasm compression. MRI, magnetic resonance imaging.

Fig. 2. Post-operative MRI control. Coronal, gadolinium-enhanced, and T1-weighted MRI showing complete sellar gangliocytoma resection 1 year after transsphenoidal transnasal surgery. MRI, magnetic resonance imaging.

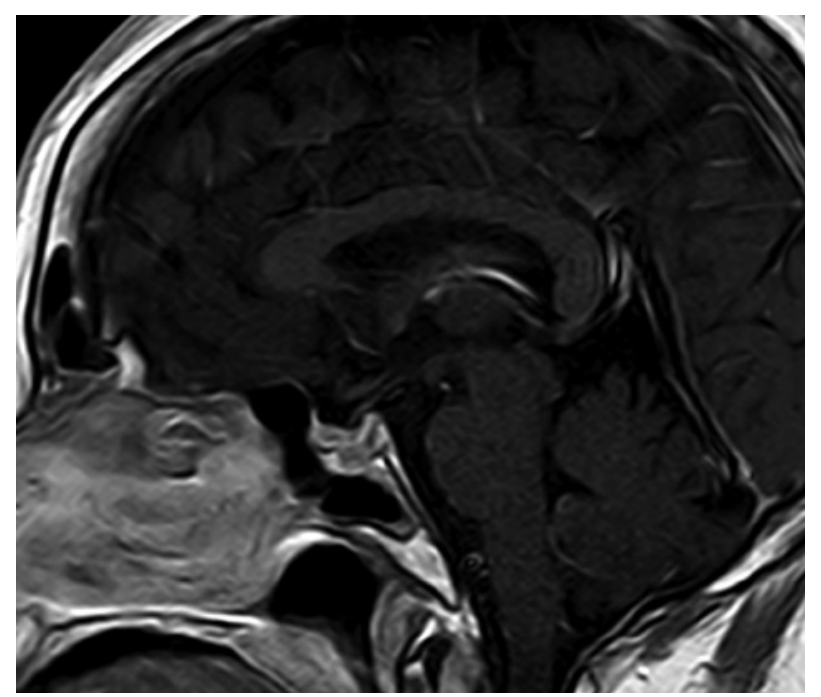

and adenohypophyseal cells were positive for ACTH and cytokeratin CAM 5.2, and negative for GH, LH, prolactin, and TSH (Fig. 3c, d). Electron microscopy displayed large cells with welldefined endoplasmic reticulum and nucleoli, as well as interdigitated cellular processes with some secretory granules.

\section{Discussion/Conclusion}

We presenta case of silent SG with an undefined corticotrope proliferation. We considered it a silent tumour, even when a full work-up for a diagnosis of Cushing's syndrome was missing, due to the cortisol - ACTH axis was normal after successful tumour resection, and on the other hand, diabetes mellitus, arterial hypertension, and central obesity did not change. The pathological diagnosis of the pituitary tissue was not completely clear, and the differential diagnoses are adenoma or hyperplasia.

There have been 3 reported cases of SG associated with pituitary hyperplasia (PH) [5-7]. PH is characterized by a polymorphic, hypercellular population with enlarged acini, 


\section{Case Reports in Neurology}
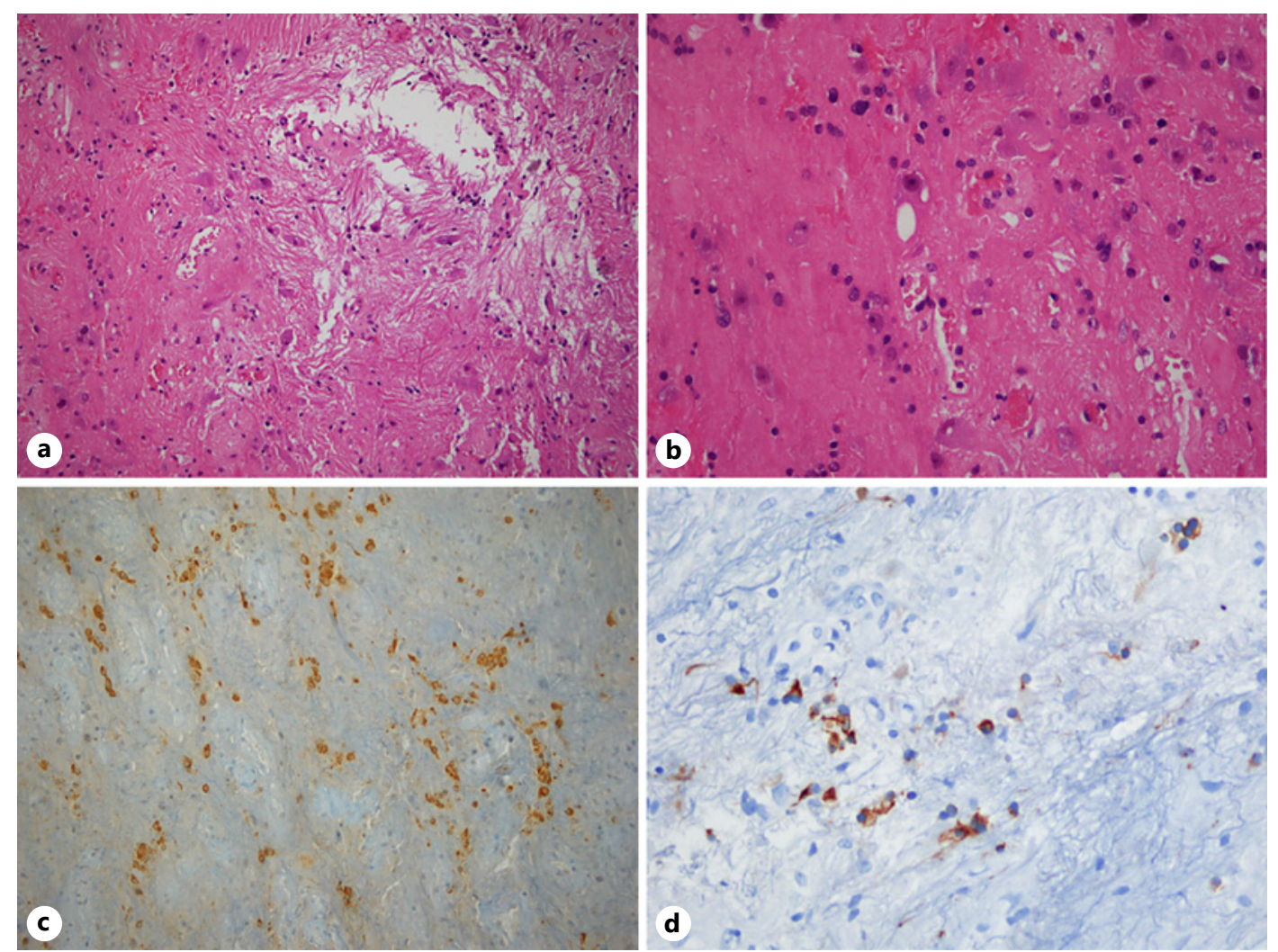

Fig. 3. a, b $(\times 20, \times 40)$ Multipolar neurons (ganglion cells) with prominent nucleoli and Nissl bodies, and round mononuclear cells (adenohypophyseal cells) mixed with ganglion cells. c $(\times 20)$ ACTH immunohistochemistry. d $(\times 40)$ CAM 5.2 immunohistochemistry showing reactivity exclusively in adenohypophyseal cells.

and an intact reticulin network [8]. Only the case reported by Asa and colleagues [7] in 2019 was in line with these criteria. Our case is similar to the case reported by Asa et al. [5] in 1984 , in which adenohypophyseal cells were found in the neuronal tumour and had enhanced ACTH secretion. However, due to the finding of a small population of adenohypophyseal cells producing GH, which suggests a polyclonal nature, Asa and colleagues [7] considered the diagnosis of an adenoma unlikely. The histological material and information available were not enough to differentiate between PA and hyperplasia for our particular case.

SGs are rare lesions, accounting for $<1 \%$ of sellar tumours [2]. Cossu and colleagues [4] reported 130 SG cases up until 2015, and our group found 207 up until February 2021 (Table 1; for all online suppl. material, see www.karger.com/doi/10.1159/000517368). Table 1 shows the demographic, clinical, and pathological characteristics of SGs, as well as the treatment strategy used. The prevalence of SG in institutional case series of sellar masses ranges between 0.05 and $5.0 \%[6,9]$. There were no clinical or laboratory characteristics to clearly differentiate an SG or mixed SG-PA from an isolated PA.

In neuroimaging, differential diagnoses for gangliocytomas are solid pituitary lesions, generally not calcified and without enhancement rings. Small, silent gangliocytomas can be underdiagnosed and preoperatively considered PAs. The definitive diagnosis for SG is postoperative and unexpected as they are extremely rare tumours. Cossu et al. [3] propose that MRI may assist in the differential diagnosis between SG and PAs. SGs are hypointense in both 
Table 1. Demographic, clinical, radiological, and treatment characteristics of patients with SGs

\begin{tabular}{|c|c|c|c|c|}
\hline \multirow[t]{2}{*}{ Characteristic } & \multicolumn{2}{|c|}{ Cossu et al. [4] } & \multicolumn{2}{|c|}{ Our review } \\
\hline & ISG & mixed SG-PA & ISG & mixed SG-PA \\
\hline$n(\%)$ & $19(15)$ & $111(85)$ & $43(21)$ & $164(79)$ \\
\hline \multicolumn{5}{|l|}{ Demographic } \\
\hline Age, mean (SD) & 43 & 44 & $41(19)$ & $44(12)$ \\
\hline Female, $n(\%)^{*}$ & $13(70)$ & $86(76)$ & $26(65)$ & $128(79)$ \\
\hline Radiological invasion, $n(\%)^{*}$ & $5(38)$ & $30(42)$ & $23(79)$ & $103(84)$ \\
\hline \multicolumn{5}{|l|}{ Symptoms of hormonal hypersecretion, $n(\%)^{*}$} \\
\hline Acromegaly & $6(32)$ & $61(55)$ & $11(28)$ & $87(54)$ \\
\hline Acromegaly and hyperprolactinemia & - & $11(10)$ & $2(5)$ & $4(3)$ \\
\hline Hyperprolactinemia & $7(37)$ & $17(15)$ & $4(10)$ & $13(8)$ \\
\hline Cushing's disease & $3(16)$ & $7(6)$ & $7(18)$ & $11(7)$ \\
\hline Silent & - & $15(14)$ & $12(30)$ & $42(26)$ \\
\hline Cushing's disease and hyperprolactinemia & - & - & - & $2(1)$ \\
\hline Other ${ }^{\mathrm{a}}$ & - & - & $4(10)$ & $1(1)$ \\
\hline \multicolumn{5}{|l|}{ Management, $n(\%)$} \\
\hline Surgery alone or combined & $14(70)$ & $93(67)$ & $36(84)$ & $160(98)$ \\
\hline Surgery alone & - & - & $30(70)$ & $122(74)$ \\
\hline Surgery and radiotherapy & - & - & $2(5)$ & $12(7)$ \\
\hline Surgery and radiosurgery & - & - & $0(0)$ & $1(1)$ \\
\hline Surgery and pharmacotherapy & - & - & $2(5)$ & $17(10)$ \\
\hline Surgery, any radiation therapy, and pharmacotherapy & - & - & $2(5)$ & $7(4)$ \\
\hline Surgery and radiotherapy and chemotherapy & - & - & $0(0)$ & $1(1)$ \\
\hline Not specified & - & - & $0(0)$ & $4(2)$ \\
\hline Incidental finding at autopsy & - & - & $7(16)$ & $0(0)$ \\
\hline Death at any time after treatment & - & - & $3(7)$ & $2(1)$ \\
\hline
\end{tabular}

Results of a systematic review in MEDLINE. See online suppl. Table 1 in supplementary information individual patient data.

SG, Sellar gangliocytomas; ISG, isolated sellar gangliocytoma; Mixed SG-PA, mixed sellar gangliocytoma and pituitary adenoma.

*Missing data were excluded to calculate percentages.

ancludes: diabetes insipidus, hypothyroidism, syndrome of inappropriate secretion of TSH, and pituitary insufficiency.

T1 and T2 sequences and have heterogeneous contrast enhancement, compared to typical PA isointensity in T1 and homogeneous enhancement with contrast, if present (unless the condition is a large macroadenoma, which has heterogeneous enhancement and can display cysts). Other differentials are lymphocytic hypophysitis, non-thrombosed perisellar aneurysms, germinomas, granular cell tumours, soft tissue sarcomas, and metastasis.

Currently, the first-line treatment for SG is surgery through a transsphenoidal approach, and complete resection is commonly achieved without major complications [4]. The prognosis for mixed SG-PA parallels the subtype of the associated PA [10]. To date, no malignant SGs have been reported. We found 2 malignant mixed SG-PAs due to pituitary carcinomas (online suppl. Table 1). 
The association between SG and PA is controversial. Three main hypotheses have been proposed to explain the tumourigenesis of mixed SG-PA [11]. The first hypothesis states that PA emerges from prolonged stimulation by hypothalamic hormones, which are produced by the SG. There are several arguments against this hypothesis. Firstly, PAs would be preceded by PH, but only 3 cases have been reported [5-7]. Secondly, there was no increase in prolactinoma incidence in multiparous women, who commonly present with $\mathrm{PH}$ [12]. Thirdly, the association between the hypothalamic hormones of SGs and the corresponding pituitary hormone in PA is inconsistent [4]. Fourthly, Ikeda and colleagues [13] probed monoclonality between SG and PA in one case of mixed SG-PA.

The second hypothesis suggests that PA and SG originate from a single common progenitor/stem cell. The expression of NeuN, a postmitotic neuronal marker, was found in $26 \%(9 / 31)$ of pituitary tumours without a neuronal component [14]. This fact controverts a common progenitor cell linage, as neuronal markers expression in PA is not exclusive for mixed SG-PA [11].

The last hypothesis proposes that mixed SG-PA may originate by transdifferentiation of a previous PA. Firstly, several cases describe a cell population with morphologic characteristics in between adenohypophyseal cells and neurons (Table 1; for all online suppl. material, see www.karger.com/doi/10.1159/000517368). Secondly, PA and SG have a common immunohistochemical-profile: the majority of mixed SG-PA have the same pituitary hormone profile in both tumour components [4], Pit-1 (a pituitary-specific transcription factor) was found in the neuronal component of 7 of 10 cases of mixed SG-PA [11], and neuronal markers were present in adenoma cells of mixed SG-PA $[4,11]$. Lastly, Ikeda and colleagues [13] performed a HUMARA analysis in neuronal, adenomatous, and intermediate cells from a mixed SG-PA and found monoclonality between the 3 cell populations. Altogether, evidence suggests that SGs originated from adenoma cells by transdifferentiation.

This report has some limitations. Unfortunately, due to missing previous medical records, the description of clinical signs suspicious for Cushing's syndrome and its full work-up is lacking. We concluded the patient did not have Cushing's syndrome because (1) tumour resection was successful without tumour recurrence at follow-up, (2) 7 months after surgery, the cortisol axis was normal, and (3) at follow-up, the patient persisted with an elevated $\mathrm{HbA1c}$, arterial hypertension, and the same body fat distribution. Regarding immunohistochemistry studies at our lab, we do not have stains for hypothalamic hormones, especially CRH.

In conclusion, SGs are rare, low-grade neoplasias commonly associated with PA. Clinical and laboratory characteristics do not differentiate between SG and PA. In contrast, tumour features on MRI may aid the clinician who suspects SG. Treatment and prognosis of SGs resemble those of PAs. Currently, the transdifferentiation hypothesis dominates tumourigenesis research for both SG and PAs [15]. SGs could be the final stage in the continuum of differentiation from normal to neoplastic cells into the pituitary gland. Immunohistochemistry and genomic studies on SGs may provide further insight into PA tumourigenesis.

\section{Acknowledgements}

The authors would like to thank the patient for all her support and disposition with the report and Valentina Guatibonza for his support in providing the patient's medical record and images.

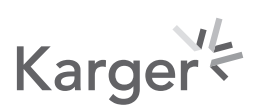




\section{Case Reports in Neurology}

\begin{tabular}{l|l}
\hline Case Rep Neurol 2021;13:475-482 \\
\hline DOI: 10.1159/000517368 & $\begin{array}{l}\text { ○ 2021 The Author(s). Published by S. Karger AG, Basel } \\
\text { www.karger.com/crn }\end{array}$ \\
\hline
\end{tabular}

Quiroga-Padilla et al.: Sellar Gangliocytoma

\section{Statement of Ethics}

Written informed consent was obtained from the patient for publication of this case report and the accompanying images. The study protocol conformed to the ethical guidelines of the 2013 Declaration of Helsinki. Approval by an Ethics Committee was not necessary as retrospective data is presented, no experimental treatments or other procedures are involved, and this publication does not compromise patient confidentiality.

\section{Conflict of Interest Statement}

The authors declared there are no potential conflicts of interest concerning the research, authorship, and/or publication of this article.

\section{Funding Sources}

This research received no specificgrant from any funding agency in the public, commercial, or not-for-profit sectors.

\section{Author Contributions}

R.A., E.J.H., P.E., and D.G.D. diagnosed the patient, and E.J.H. and D.G.D. were involved in the treatment and follow-up of the patient. P.J.Q.P. and D.G.D. were involved in writing the draft, which was further modified after critical inputs from R.A., E.J.H., and P.E. All the authors agreed upon the final version of the article.

\section{References}

1 McNeill KA. Epidemiology of brain tumors. Neurol Clin. 2016;34(4):981-98.

2 Mete O, Lopes MB. Overview of the 2017 WHO classification of pituitary tumors. Endocr Pathol. 2017;28: 228-43.

3 Cossu G, Brouland JP, La Rosa S, Camponovo C, Viaroli E, Daniel RT, et al. Comprehensive evaluation of rare pituitary lesions: a single tertiary care pituitary center experience and review of the literature. Endocr Pathol. 2019;30:219-36.

4 Cossu G, Daniel RT, Messerer M. Gangliocytomas of the sellar region: a challenging diagnosis. Clin Neurol Neurosurg. 2016;149:122-35.

5 Asa SL, Kovacs K, Tindall GT, Barrow DL, Horvath E, Vecsei P. Cushing's disease associated with an intrasellar gangliocytoma producing corticotrophin-releasing factor. Ann Intern Med. 1984;101:789-93.

6 Li JY, Racadot O, Kujas M, Kouadri M, Peillon F, Racadot J. Immunocytochemistry of four mixed pituitary adenomas and intrasellar gangliocytomas associated with different clinical syndromes: acromegaly, amenorrhea-galactorrhea, Cushing's disease and isolated tumoral syndrome. Acta Neuropathol. 1989;77: 320-8.

7 Asa SL, Ezzat S, Kelly DF, Cohan P, Takasumi Y, Barkhoudarian G, et al. Hypothalamic vasopressinproducing tumors: often inappropriate diuresis but occasionally cushing disease. Am J Surg Pathol. 2019; 43:251-60.

8 De Sousa SMC, Earls P, McCormack AI. Pituitary hyperplasia: case series and literature review of an underrecognised and heterogeneous condition. Endocrinol Diabetes Metab Case Rep. 2015;2015:150017.

9 Courville CB. Ganglioglioma: tumor of the central nervous system; review of the literature and report of two cases. Arch NeurPsych. 1930;24:439-91.

10 Kleinschmidt-DeMasters BK, Lopes MB, Prayson RA. An algorithmic approach to sellar region masses. Arch Pathol Lab Med. 2015;139:356-72.

11 Lopes MB, Sloan E, Polder J. Mixed gangliocytoma-pituitary adenoma: insights on the pathogenesis of a rare sellar tumor. Am J Surg Pathol. 2017;41:586-95. 
12 Melmed S. Mechanisms for pituitary tumorigenesis: the plastic pituitary. J Clin Invest. 2003;112:1603-18.

13 Ikeda H, Ma W, Yoshimoto T. Demonstration of monoclonality in coexisting GH-producing adenoma and neuronal tissue. Med Sci Monit. 2003;9:CS47-52.

14 Nguyen MT, Lavi E. Pituitary adenoma-neuronal choristoma is a pituitary adenoma with ganglionic differentiation. Exp Mol Pathol. 2015;99:628-31.

15 Melmed S. Pathogenesis of pituitary tumors. Nat Rev Endocrinol. 2011;7(5):257-66. 